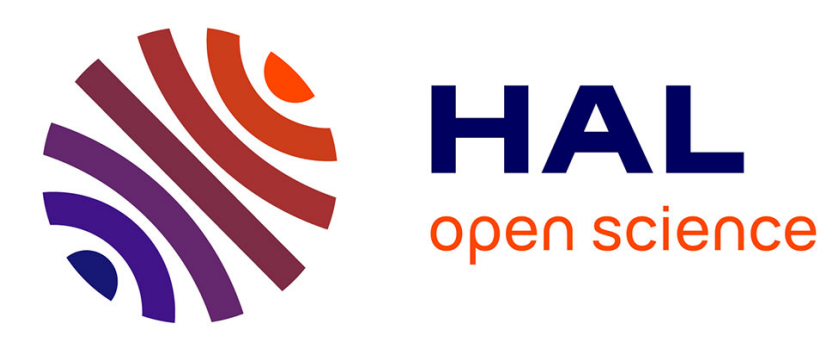

\title{
Emotional Labour of Caregivers Confronted With Aggressive Brain-injured Patients
}

\author{
Magali Huet, Lionel Dany, Thémis Apostolidis
}

\section{To cite this version:}

Magali Huet, Lionel Dany, Thémis Apostolidis. Emotional Labour of Caregivers Confronted With Aggressive Brain-injured Patients. Archives of Psychiatric Nursing, 2017, 10.1016/j.apnu.2017.11.026 . hal-01648423

\section{HAL Id: hal-01648423 \\ https://hal-amu.archives-ouvertes.fr/hal-01648423}

Submitted on 26 Nov 2017

HAL is a multi-disciplinary open access archive for the deposit and dissemination of scientific research documents, whether they are published or not. The documents may come from teaching and research institutions in France or abroad, or from public or private research centers.
L'archive ouverte pluridisciplinaire HAL, est destinée au dépôt et à la diffusion de documents scientifiques de niveau recherche, publiés ou non, émanant des établissements d'enseignement et de recherche français ou étrangers, des laboratoires publics ou privés. 


\section{Accepted Manuscript}

Emotional Labour of Caregivers Confronted With Aggressive Brain-injured Patients

Magali Huet, Lionel Dany, Thémistoklis Apostolidis

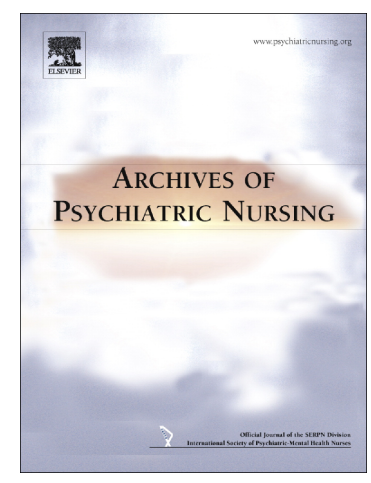

PII: $\quad$ S0883-9417(17)30160-7

DOI: $\quad$ doi:10.1016/j.apnu.2017.11.026

Reference: $\quad$ YAPNU 51039

To appear in: $\quad$ Archives of Psychiatric Nursing

Received date: $\quad 28$ March 2017

Revised date: $\quad 10$ August 2017

Accepted date: $\quad 18$ November 2017

Please cite this article as: Magali Huet, Lionel Dany, Thémistoklis Apostolidis , Emotional Labour of Caregivers Confronted With Aggressive Brain-injured Patients. The address for the corresponding author was captured as affiliation for all authors. Please check if appropriate. Yapnu(2017), doi:10.1016/j.apnu.2017.11.026

This is a PDF file of an unedited manuscript that has been accepted for publication. As a service to our customers we are providing this early version of the manuscript. The manuscript will undergo copyediting, typesetting, and review of the resulting proof before it is published in its final form. Please note that during the production process errors may be discovered which could affect the content, and all legal disclaimers that apply to the journal pertain. 


\title{
Emotional labour of caregivers confronted with aggressive brain-injured patients
}

Running head: Emotional labour of caregivers

Magali Huet ${ }^{1}$, Lionel Dany $\mathrm{PhD}^{1,2,3}$ and Thémistoklis Apostolidis $\mathrm{PhD}^{1}$

${ }^{1}$ Aix-Marseille Université, LPS EA849, 13621, Aix-en-Provence, France

${ }^{2}$ APHM, Timone, Service d'Oncologie Médicale, 13385, Marseille, France

${ }^{3}$ Aix-Marseille Université, ADES UMR 7268, 13344, Marseille, France

\section{Corresponding Author:}

Pr. Lionel Dany, Laboratoire de Psychologie Sociale EA 849, Maison de la Recherche, Aix Marseille Université, 29 avenue Robert Schuman, 13621 Aix-en-Provence, France.

Telephon: 0033 (0)4 13553819

E-mail address: Lionel.Dany@univ-amu.fr

\begin{abstract}
Background: Aggressive behaviours are common with people who have suffered brain injuries and induce difficult emotions amongst certified nursing assistants and medical-psychological assistants who take care of them. These caregivers carry out emotional labour whose content and strategies are little known.

Aim: The study explores the emotional labour of certified nursing assistants and medicalpsychological assistants faced with the aggressive behaviours of brain-injured patients. Methods: Semi-structured interviews were conducted with 37 caregivers. Interviews were analysed via a thematic content analysis.
\end{abstract}


Results: The analysis shows that the emotional labour of caregivers varies in accordance with the state of "consciousness" or "non-consciousness" that they attribute to the brain-injured patient with regard to this aggressive behaviour. This is a deep acting strategy. Moreover, caregivers shut off their emotions in order not to transmit them to the patient. This surface acting has the first objective for the caregiver of maintaining control of the situation and a second objective of protecting the patient emotionally and therefore of being perceived as a "good" caregiver. Emotional labour also meets a need to preserve the professional self-image and professional status negatively affected in the interaction with the aggressive brain-injured patient.

Conclusions: Our study specifies the different strategies of the emotional labour of caregivers and their circumstances of use when they are confronted with aggressive behaviour by brain-injured patients. Targeted support for this emotional labour, such as training and practical analysis, is essential for the development of care practices promoting a caring relationship.

\section{Keywords}

Aggression, brain injuries, emotions, professional-patient relations, qualitative research

\section{Introduction}

Behavioural problems are common after a traumatic brain injury (TBI) or stroke (Chan, Campayo, Moser, Arndt, \& Robinson, 2006; Ponsford, 2013a) and can persist for several years (Fleminger \& Ponsford, 2005). Amongst other factors, they result from cognitive disorders (i.e., disinhibition, executive functions), and/or psychopathology (i.e. depression, anxiety, personality change). The behaviours are manifested through a disorder of control, such as aggression, or a disorder of drive (i.e., apathy) (Azouvi, Vallat-Azouvi, \& Belmont, 2009) and are responsible for difficulties in social interactions (Ponsford, 2013b). 
In general, caregivers, who are faced with difficult behaviours, feel negative emotions (i.e. anger, fear, guilt), and anxiety and are given additional workloads (Jenkins, Rose, \& Lovell, 1997). To preserve the caring relationship with the patient who presents difficult behaviours, caregivers must work on their own emotions (Farrell, Shafiei, \& Salmon, 2010). The expression of emotions obeys rules of emotional display, that is to say, social conventions dictating the emotions that must be expressed in a given situation and how to express them.

The concept of emotional labour (Hochschild, 1983) has been developed to examine the emotional demands of work and the individual styles of responding to these emotional demands. Emotional labour refers to the process by which workers are expected to manage their feelings and their emotions in accordance with organizationally defined rules and guidelines (Hochschild, 1983). By their emotional labour, workers can "create and maintain a relationship, a mood, or a feeling" (Hochschild, 1983, p. 440). Applied to situations of care, the emotional labour of caregivers involves producing emotions and affects in accordance with the professional social norms. This emotional labour also aims to maintain the well-being of the patient and preserve the care relationship. Emotional labour by caregivers is performed on the basis of emotional dissonance or emotional harmony experienced in response to that which concerns the patient (i.e. pain, emotions, uncertainty about treatment or other events related to the care context) (Mann, 2005). Emotional dissonance requires a resolution of the conflict between the emotions experienced and those that the caregiver thinks they should feel with regard to personal or socio-professional expectations.

Two main processes of emotional labor - surface acting and deep acting - represent how people manage emotions to meet work role demands (Hochschild, 1983). In surface acting, professionals modify and control their emotional expressions (Brotheridge \& Grandey, 2002). For example, caregivers may exaggerate or fake a smile when in a bad mood or interacting with a difficult braininjured person. In other words, surface acting refers to the expression of emotions that are not felt by the professional and internal feelings are left intact. Deep acting is the process of controlling internal thoughts and feelings to meet the mandated display rules (Brotheridge \& Grandey, 2002). This 
strategy implies that the professional experiences emotion in "depth". For example, a caregiver may imagine himself in the difficult situation of one patient to try to feel empathy and look concerned.

The contextual approach of emotional labour emphasizes the role of social factors/constructs in emotional labours (Grandey, 2000; Syed, 2008). Emotions are socially regulated, prescribed and learned in relation to social contexts and cultures which emphasize some societal norms, ways of thinking and beliefs. This contextual approach is particularly relevant for understanding the impact and role of psycho-social factors (such as beliefs and lay thinking) that operate when professionals are confronted with uncertainty and ambiguity in their work activities. For example, persuasion strategies, avoidance, and search for a compromise were observed for caregivers taking care of patients who present difficult behaviours, such as brain-injured people (Michaelsen, 2012). Persuasion is supported by the belief that the patient will comply with the role that the caregiver assigns to them. Avoidance involves an emotional distance for the caregiver. Persuasion and avoidance can progress to the search for a compromise, which involves considering the position that the patient wishes to take in care, and presupposes the "intentionality" or the "consciousness" of the patient (Huet, Dany, \& Apostolidis, 2016).

The social representations (SRs) theory (Moscovici, 1973) could offer a heuristic way of studying beliefs and lay thinking that could influence emotional labour in the context of the caregiver/patient relationship. This theory "offers a model of social knowledge, its social construction, transformation and distribution, and describes the function of experience and knowledge in social practices" (Flick, 1996, p.70). SRs are a system(s) of values, ideas and practices which permit individuals to orient themselves in their material and social world and to master it, and to enable communication among the members of a community (Moscovici, 1973). SRs are defined as socio-cognitive structure, a form of knowledge that is socially developed and shared, having a practical aim and contributing to the construction of a common reality for a social body (Jodelet, 1991; Wagner \& Hayes, 2005). SRs have four essential functions, which are, understanding and explaining reality (function of knowledge), defining and maintaining individual and group identity (identity function), guiding behaviours and 
practices (guidance function), and justifying behaviours and standpoints a posteriori (justifying function) (Abric, 1994).

From a socio-psychological perspective, the purpose of our study is to understand the specificities and contributions of emotional labour by caregivers to building and maintaining a benevolent care relationship when they are confronted with aggressive behaviour by brain-injured persons. This study aims to identify the strategies used to manage the aggressive behaviour of patients. We also aim to analyse the relations between these strategies and socio-cognitive constructs (such as social representations), by exploring how these constructs constitute a basis for understanding aggressive behaviours and for explaining the implementation of the strategies associated with emotional labour.

\section{Methods}

\section{Design}

Our study is a qualitative exploratory study. We conducted semi-structured research interviews with caregivers in one functional rehabilitation centre and in one specialist residential care home in France. Patients admitted to these institutions have a variety of disorders (e.g., cognitive, motor, sensory). The intensity of the disorders varies from an extreme deficiency state (e.g., chronic vegetative state), a minimally conscious state or locked-in-syndrome (American Congress of Rehabilitation Medicine, 1995; Giacino et al., 2002; Jennet \& Plum, 1972) to a minor deficiency state (e.g., difficulty in organizing his / her actions in a new task). Thus, some patients are dependent on others for all the acts of daily life and others are autonomous, and require light assistance or planning of their environment for certain activities. Between these two extremes, all levels of impairment and dependence are encountered. In France, caregivers who perform basic care and who help persons with brain injuries to perform everyday tasks are certified nursing assistants (CNAs) and medical-psychological assistants. The use of semi-structured interviews offers a safe, supportive and respectful environment for the 
participant to express emotions and experiences. The methods of the study are presented in accordance with the consolidated criteria for reporting qualitative research checklist (COREQ) (Tong, 2007).

\section{Participants}

Thirty-seven caregivers participated in the interviews and none dropped out. These were all caregivers working with victims of traumatic brain injury or stroke, who work in a functional rehabilitation centre or a specialist residential care home. The socio-demographic data and the socio-professional data of our sample are described in Table 1. The large proportion of women is explained by the significant feminization of these professions in France (Bessière, 2005).

\section{Insert Table 1}

\section{Ethical considerations}

In each facility, with the agreement of management, the first author met CNAs and medicalpsychological assistants at a meeting to present the research, its aim, the ethical conditions of participation (i.e., volunteering and confidentiality) and we proposed that they participate in semistructured research interviews. Caregivers were told they could withdraw from the research at any time. A note recapitulating the ethical conditions necessary for participation was given to the caregivers. The interviewer made sure that each participant had given their written consent before the interview. Ethical approval for this research was obtained from the University Ethics Committee of Aix-Marseille University, France.

\section{Data collection}


Thirty-seven interviews were conducted by the first author who has 5 years of experience in this field and as a psychologist in this type of care facility. The interviews were structured from an interview guide constructed previously (Smith, 1995). In designing it, we determined the topics which had to be discussed with the participants to answer our research questions. For each topic, we developed open and neutral questions. We organized the topics and their associated questions from general to more specific ones. The guide included two parts consisting of a set of open questions. The questions' items are presented in Table 2. Other questions proposed were based on the speech of the participants in order to examine its informative and emotional content in depth (i.e., reformulation of the expressed emotion). These questions involved the spontaneous emergence of aggressive behaviours in the discourse of all the participants (e.g., Does the brain-injured person present behaviour disorders?) and the explanations provided by the caregivers about these aggressive behaviours (e.g., How do you differentiate them from other care situations?). The guide was modified after the first interviews. We changed a few questions to improve the understanding of some questions, and introduced other questions to expand on the content of the speech. Its stabilized version was obtained after the seventh interview. The interviews were conducted between September 2013 and July 2014, in the caregiver's workplace in a room where confidentiality could be maintained and which provided a favourable environment for the expression of emotional content. An audio recording was made. At the end of each interview, the participant was offered a debriefing on the interview itself. We stopped scheduling interviews with caregivers when we reached saturation of our data. Their duration varied from 24 to 129 minutes. Their content was transcribed and anonymized.

\section{Insert Table 2}

\section{Data analysis}

Each interview was subject to a thematic content analysis (Flick, 2014). Thematic content analysis consists in building a thematic structure based on an analysis of the unit of sense of the interviews. A 
unit of sense is the part of the data, ranging from words to paragraphs, which gives meaning to the speech. These units of sense are grouped by theme and sub-theme, in order to build a global thematic structure. All the interviews were used to build the thematic structure. The first two authors each read the first interview attentively in order to identify the units of sense. Each modified their initial thematic structure via content analysis of the following interviews. These modifications consisted in adding to and reorganizing the themes and sub-themes. In a working group, the authors shared the coding for the units of sense, agreed on an analysis of the ambiguous units of sense, and developed a common thematic structure. This common thematic structure was stabilized by the tenth interview. An extract of this final thematic structure of the thematic content analysis is presented in Table 3 . These first interviews were analysed again using the final thematic structure. Another level of analysis was carried out by identifying the links between the different sub-themes of the themes. The participants did not intervene in the thematic content analysis. The first author gave the participants a summary of the results of the research. The participant characteristics (age, sex, etc) were taken into account during the thematic analysis to explore their potential influence on the discourse.

\section{Insert Table 3}

\section{Results}

A significant proportion of caregivers' speech was devoted to aggressive behaviours. Analysis showed that aggressive behaviour by brain-injured persons caused negative emotions among caregivers, such as fear, anger, surprise or a sense of powerlessness. The emotional experience of caregivers differed according to the perceived state of "consciousness" of the brain-injured person and it expressed itself in accordance with the anticipated effects of the transmission of emotions. Emotional labour was 
linked to the preservation of the self-image and professional status of caregivers. The results presented did not differ in accordance with the participants' characteristics, such as age, gender, occupation and number of years of service.

\section{A different emotional experience according to the state of "consciousness" of the brain- injured person}

We observed that management of emotions was oriented according to the perceived state of "consciousness" or "non-consciousness" attributed to the brain-injured person. This approach was shared by 33 participants during the interview.

Differentiation between the "conscious" and "non-conscious" patient is related to the person's capacity to understand the world, and their own acts, disorders or disability. To distinguish between the "conscious" or "non-conscious" patient or the situations in which the patient has different levels of consciousness, caregivers rely on the communication with them and the observations and/or thoughts of other professionals about them (i.e. medical file, speech). This state of consciousness is the result of a lay diagnosis made by the caregivers. The "non-conscious" patients are not necessarily the ones with the most unfavourable medical diagnosis (e.g., chronic vegetative state or minimally conscious state), and "conscious" patients are not necessarily the ones who have the most favourable medical diagnosis (e.g., slight cognitive difficulties).

A "conscious" patient is thought to know why they are aggressive. This state of consciousness is associated with perceived conscious control. Furthermore, they are supposed to be capable of managing, anticipating or premeditating their own actions. Therefore, for caregivers, the "conscious" patient has the capacity to control their behaviour and to resort to non-aggressive behaviour. Caregivers consider that aggressive behaviour is targeted at them intentionally. Therefore, they feel negative emotions which cause suffering.

" $\{$ Patients $\}$ who have all their mental faculties and who allow themselves to speak very badly.

That I can't accept. (...) We get hit by patients but afterwards, when they $\{\ldots\}$ aren't 
conscious, you can't say anything. It's not their fault." (Functional rehabilitation centre, 37 years of age, 15 years of care experience and service).

Conversely, the patient presumed to be "non-conscious "of their behaviour has not sufficient understanding of the situation to respond with non-aggressive behaviour. These patients are perceived as not having conscious control. Caregivers did not consider themselves as the target of the behaviour, only as a person who interacts with the brain-injured patient at the wrong time. The emotions felt faced with the aggressive behaviour of a "non-conscious" patient are more easily managed.

"There's an aggressive patient, it does not bother me at all. I hold out my hand to them, they hit my hand, it makes them feel good, I talk to them about something else, it's over. They get angry for two minutes, but it has no effect on me, it neither annoys me nor frustrates me...Others have had more effect. I don't react the same to each resident. Perhaps because for me there is not the same notion of consciousness. For me they are violent but not on purpose." (Specialist residential care home, 36 years of age, 1 year of care experience and service)

\section{A categorization that guides and legitimates professional practices}

The responses that caregivers gave in the interaction varied according to the categorization of brain-injured patients and according to the state of "consciousness" that they perceived. The perception of mental states (as an explanation of the situation and guide for action) is a key factor in this process of categorization. When the person is considered "conscious" of their or her actions, disorders or condition, the caregivers target their actions at the person (i.e., correcting their behaviour or words, explaining the social rules). These strategies were common to all the caregivers. When the brain-damaged person is considered as "unconscious", professional practices are targeted rather at the environment (i.e., isolating, doing nothing) or at the caregiver themselves by accepting the person's behaviours. These types of professional practices were mentioned by 32 participants. This alternative requires emotional work on the part of caregivers, including a distancing from the patient's behaviours. In this extract, this 
medical-psychological assistant explains the orientation of her interventions according to this state of "consciousness":

"Those who have the faculty, we must explain to them that the behaviour is unacceptable ... for reasons of community, for reasons of right or wrong, that it must not happen here. And for those who do not have the ability to understand, you have to defuse the crisis, try to divert attention and make them move on to something else or isolate them in some cases." (Specialist residential care home, medical-psychological assistant, 34 years of age, 15 years of care experience and service)

\section{Suppressing emotions in order not to 'transmit' them}

In some cases, caregivers suppress their emotions faced with aggressive behaviour. This strategy was common to 25 caregivers. This surface work prevents the violence of the behaviour being increased by transmitting their own negative emotions to the brain-injured person. This reasoning is based on a positive relationship between the intensity of the emotions experienced by a person and the intensity of the aggressive behaviour, which is the expression of their emotions. These caregivers explained that the aggressive behaviour becomes more violent, unless they have effective strategic ways to intervene. By containing the level of violence initiated by the patient, the caregiver has a range of potentially effective interventions for calming aggressive behaviour. When the behaviour is too violent, the caregiver finds themselves powerless and loses control of the situation. This feeling in turn generates negative emotions for the caregiver. Thus, they try to protect the patient and themselves emotionally. These extracts of interviews illustrate the strategy of suppressing emotions in order not to transmit them:

"I try to stay calm. I especially don't get excited. Because the more one gets upset, the more violent they get. So, on the contrary, one must try to appease them." (Specialist residential care home, medical-psychological assistant, 39 years of age, 17 years of care experience, 9 years of service). 
"We give him a moment to calm down and then after we return to see him. And always trying to humour him, be gentle and nice... If you are attacked by someone, and we respond aggressively, it escalates. So, the goal is to calm the person down. To defuse the aggression.” (Functional rehabilitation centre, CNA, 42 years of age, 24 years of care experience and service)

\section{Preserving professional status}

Caregivers use several strategies to manage their emotions from the perspective of preserving their status with regard to the aggressive brain-injured patient. The collective nature of these strategies was reflected in a large number of caregivers who referred to one or more of them during the interview. An initial strategy, expressed by 25 caregivers, is to control the expression of their emotions with the aim of hiding them (i.e. surface acting) and to let the brain-injured patient believe that they are not affected by their behaviour. Emotion is perceived as a weakness by caregivers. A second strategy employed is to remind the aggressive patient that they have the support of senior management or to actually call on this support. They rely on the authority figures in the facility to back up their position, which they feel is threatened in their care relationship. Caregivers use a social support that they perceive as available and effective. This method was mentioned by 24 caregivers. A third strategy is to bring the patient back into line, by reminding them of the social conventions and rules which regulate the behaviour of all in any interpersonal interaction. This practice was spelled out by 32 caregivers. The speech of caregivers showed that these strategies were a way for them to show the brain-injured person, themselves and other professionals, that they were maintaining control of the relationship. Thus, caregivers seek to maintain a relational position of "superiority" and "authority". This major issue is present whatever the perceived state of consciousness of the brain-injured person.

These extracts from two interviews with CNAs show the link with the first strategy and their position in their care relationship with an aggressive brain-injured person: 
"From the beginning, we didn't show we were afraid. Even if sometimes he startles us. The first time he hurt me, I forced myself, and I said I have to return now. A little like when you fell and ... I said that I have to return, otherwise I won't be able to return later, I'll be scared. $\{\ldots\}$ I said " $\{\ldots\}$ I have to show him that he does not have the upper hand". (Specialist residential care home, 43 years of age, 7 years of care experience and service).

“No, I prefer to go away. I won't play their game, I'm going. $\{\ldots\}$ They must be respectful, we are here to help them, we're not their maid, we're not here to get it in the neck". (Functional rehabilitation centre, 37 years of age, 15 years of care experience and service)

This extract from an interview with a CNA illustrates the use of different strategies:

"If he starts to fight or insult us, at first, we say “you must be calm, don't hit us, don't insult us.". If that is not enough, well, we have to say "That's enough now! Calm down! Otherwise we will go see the director!"... Or things like that". (Specialist residential care home, 57 years of age, 12 years of care experience and service)

\section{Care of professional self-image}

The view of caregivers was that to be a "good" caregiver they have to be caring, respectful of the patient, listen, be empathetic and at the same time unaffected by the emotions of others. In 24 interviews, the caregivers explained that they set up professional practices that conform to this image of the "good" caregiver. Faced with aggressive behaviour, caregivers experience negative emotions (e.g. anger, fear) which do not correspond to this idealized professional image. Indeed, caregivers can't display anger with the brain-injured patient or fail to provide care because they are afraid of them. Thus, caregivers hide their emotions in response to the image of what a "good" caregiver should be. In these speeches, the CNAs explain this type of emotional work:

"When they tell you to remain professional, it means that you have to keep silent, you have to put up with the insult. And you go away." (Functional rehabilitation centre, 37 years of age,

15 years of care experience and service). 
"I was going to put him to bed when he kicked me in the shin, but violently, so... always the same thoughts... we swallow our tears and we continue caring and ... We don't have any choice." (Specialist residential care home, 57 years of age, 12 years of care experience and service).

“They really do anything. Now I take care of myself, I protect myself. So, I'm ... not less sensitive, but I mean I show less. I swallow my tears a little." (Specialist residential care home, 24 years of age, 4 years of care experience and service).

\section{Discussion}

Aggressive behaviours by brain-injured persons involve emotional labour for CNAs and medicalpsychological assistants. Thus, in the same way, this emotional labour, much explored in previous studies carried out in other countries, is also experienced by the-caregivers who participated in this research in the French context. These caregivers develop strategies for deep acting (experiencing emotion) and surface acting (showing emotion without experiencing it) according to the situation and the desired effect on their care relationships. Our study shows some socio-psychological characteristics that contribute to the emotional labour of TBI caregivers. These aspects refer to the common knowledge expressed by caregivers and the social processes involved in emotional labour.

Among the social factors involved in the emotional labour of caregivers, two types of element are shared. The first are related to the beliefs developed about the state of "consciousness" or "nonconsciousness" of the brain-injured patients concerning their aggressive behaviours. This state is determined collectively (e.g., medical data, pooling daily observations) and prior to confrontation with aggressive behaviours.

This cognitive reappraisal (Grandey, 2000) is a deep acting strategy that integrates a collective construction of knowledge by caregivers, and the transmission of this common knowledge amongst caregivers. The second element of the SR includes the belief that a negative emotion added to another 
negative emotion already present intensifies the first one, associated with the belief that negative emotions are harmful to the patient and positive emotions are beneficial to them (Johnson, 2015). Caregivers also use surface acting (showing emotion without experiencing it) to comply with these social beliefs present in their social space. Moreover, following these beliefs, caregivers ensure that their care relationships are benevolent. The construction of this common knowledge/these representations of caregivers about brain injured people is associated with professional, personal and collective experiences but also with reference to sets of beliefs (shared socially) about personality, overgeneralization, the use of an internal model of causation, and the separation between body and mind (Huet, Dany, \& Apostolidis, 2016).

In a context of uncertainty, social representations allow individuals to make sense of "strange" professional situations in order to make them more familiar (Jodelet, 1991), and finally more controllable. The various disorders (i.e., behavioural, cognitive, psychopathological) of the braininjured person put caregivers in situations of uncertainty when they interact with them. Caregivers don't know what the person thinks about, what are their needs or which care practice to use. In this context of uncertainty, they rely on their social representations (i.e., beliefs, common knowledge, shared values) to support their professional practices through social validation and/or the reconstruction of the experiences, thoughts and needs of the brain-injured person (e.g., to determine the "consciousness" or "non-consciousness" of the person). For example, referring to consciousness makes it possible, in fact, to "denaturalize" and thus to socialize what might be perceived only (and initially) as a mental state (Rosenthal, 1986). Finally, these representations allow us to consider both responsibility and irresponsibility and deal with uncertainty. Although, a state of consciousness usually constitutes knowledge due to self-reference, we observe, in this study, that caregivers use SRs to formulate hetero-references and categorizations of patients. Through this process, socio-cognitive constructs guide the professional practices and the emotional labour (i.e. initiation, orientation and process) of the caregivers, by making sense of difficult experiences in care situations (Huynh, Alderson, \& Thompson, 2008). 
We can highlight another function of the use of social representations by caregivers. The use of common knowledge by caregivers allows them to manage the gap between their actual and ideal job. The work with brain injured people confronts the caregivers with an important limitation: the possibility of carrying out their work "normally" (situations expected by caregivers in relation to their training). They use these beliefs to deal with this limitation, to cope with the emotional impact associated with the perceived impossibility of carrying out their work in optimal conditions.

Our study shows that caregivers use surface acting when they suppress their emotions (e.g., anger, fear) faced with aggressive behaviours. This strategy, which consists of not showing an emotional state actually experienced, allows them to maintain control of the behaviour of the brain-injured person and the situation. A feeling of loss of control would be associated with a painful emotional experience. Thus, despite the adverse effects of surface acting on the psychological health of the caregiver (Brotheridge \& Grandey, 2002; Pisaniello, Winefield, \& Delfabbro, 2012; Schmidt \& Diestel, 2014), we consider that this strategy can protect them from a difficult emotional experience.

Bringing into line the brain-injured patient who presents aggressive behaviours is a strategy of persuasion (Michaelsen, 2012). The caregiver makes known their disagreement and their experience faced with the behaviour, but they do not assess the meaning of the behaviour for the brain-injured patient. Considering the position of this patient allows a compromise to be established between the players in the relationship, favourable to the emotional labour of the caregiver and to the development of the care relationship (Michaelsen, 2012). Furthermore, considering the position of the patient receiving care is a fundamental principle of the practice of care according to the theories of care (Tronto, 1993). This strategy of bringing the patient into line questions the long-term effects on the emotional experience of the caregiver, the quality of the relationship that they have built with the patient and their perception of their care activity. This question is important because caregivers are faced with a significant number of behaviours to bring into line. 
Our study emphasizes the potential effect of the emotional experience of caregivers on their psychological health, on their quality of work life and on the quality of care. This specific knowledge of emotional labour, by CNAs and medical-psychological assistants faced with the aggressive behaviours of brain-injured people, helps us understand how this work helps or impedes the construction and preservation of a benevolent care relationship. In many ways, emotional labour can be envisaged as a coping strategy under constraint (due to professional obligations).

\section{Practical implications}

Specific knowledge about emotional labour (content, processes) should enable suitable training to be developed, offering a consideration of the causes associated with aggressive behaviours, the beliefs at work in explaining and managing aggressive behaviours by these caregivers and the effectiveness of the individual and collective coping strategies used by caregivers (e.g. suppressing emotions, handing over to another carer).

\section{Study limitations}

The first limitation of our study is in the characteristics of our sample which does not allow the results to generalised. However, the sample had a good diversity of profiles (i.e. age, length of service).

Furthermore, participants came from two specific facilities in France. Our study concerns medicalpsychological assistants, which is a profession that has no strict equivalence in other countries. In fact, the functions performed by medical-psychological assistants are similar to those performed by CNAs in the United States and healthcare assistants in the United Kingdom.

Our study aims to describe the specifics of the emotional labour of caregivers confronted with aggressive behaviours without linking them to the effect of emotional labour on the well-being of 
caregivers. This relationship can be highlighted in future studies by means of direct data (i.e. questionnaires) and indirect data (i.e. rate of turnover) on caregivers' welfare.

Future studies will examine the emotional labour of caregivers faced with other behavioural disorders of brain-injured people (e.g. the effect of disinhibition on sexual behaviour, and apathy), in order to report on the specificities of this emotional labour.

\section{Conclusion}

Aggressive behaviours of brain-injured persons involve an emotional labour among caregivers who perform basic daily care and who spend the most time with these people. Our study shows the specific strategies used, their situational conditions, the social factors involved, their objectives and their contribution to the care relationship. This knowledge is a prerequisite for the development of support work for these caregivers, in order to preserve a benevolent care relationship.

\section{Acknowledgements}

The authors thank the partner institutions for their collaboration and the caregivers who participated in our research. This research has received funding from the Fondation de France, grant number 00059759.

\section{References}

Abric, J.-C. (1994). Pratiques sociales et représentations [Social practices and representations]. Paris: Presses Universitaires de France. 
American Congress of Rehabilitation Medicine (1995). Recommendations for use of uniform nomenclature pertinent to patients with severe alterations in consciousness. Archives of physical Medicine and Rehabilitation, 76, 205-209.

Azouvi, P., Vallat-Azouvi, C., \& Belmont, A. (2009). Cognitive deficits after traumatic coma. Progress in brain research, 177, 89-110.

Bessière, S. (2005). La féminisation des professions de santé en France: Données de cadrage [The feminization of the health professions in France: Framework data]. Revue Française des Affaires Sociales, 1, 17-33.

Brotheridge, C. M., \& Grandey, A. A. (2002). Emotional labor and burnout: Comparing two perspectives of "people work". Journal of Vocational Behavior, 60, 17-39.

Chan, K. L., Campayo, A., Moser, D. J., Arndt, S., \& Robinson, R. G. (2006). Aggressive behavior in patients with stroke: Association with psychopathology and results of antidepressant treatment on aggression. Archives of Physical Medicine and Rehabilitation. 87, 793-798.

Farrell, G. A., Shafiei, T., \& Salmon, P. (2010). Facing up to "challenging behaviour": A model for training in staff-client interaction. Journal of Advanced Nursing, 66, 1644-1655.

Fleminger, S., \& Ponsford, J. (2005). Long term outcome after traumatic brain injury. More attention needs to be paid to neuropsychiatric functioning. British Medical Journal, 331, 1419-1420.

Flick, U. (2014). Thematic coding and content analysis. In U. Flick (Ed.), An introduction to qualitative research (pp. 420-438). London: Sage.

Flick, U. (1995). Social Representations. In R. Harré, J. Smith, \& L. van Langenhove (Eds.), Rethinking Psychology (pp. 70-96). London: Sage.

Giacino, J. T., Ashwal, S., Childs, N., Cranford, R., Jennett, B., Katz, D. I., Kelly, J. P., Rosenberg, J. H., Whyte, J., Zafonte, R. D., \& Zasler, N.D. (2002). The minimally conscious state. Definition and diagnostic criteria. American Academy of Neurology 58(3), 349-353. 
Gosseries, O., Demertzi, A., Ledoux, D., Bruno, M. A., Vanhaudenhuyse, A., Thibaut, A., Laureys, S., \& Schnakers, C. (2012). Burnout in healthcare workers managing chronic patients with disorders of consciousness. Brain Injury, 26(12). 1493-1499.

Grandey, A. A. (2000). Emotional regulation in the workplace: A new way to conceptualize emotional labor. Journal of Occupational Health Psychology, 5, 95-110.

Hochschild, A. R. (1983). The Managed Heart: Commercialization of Human Feeling (2nd ed.). Berkeley, CA: University of California Press.

Huet, M., Dany, L., \& Apostolidis, T. (2016). Explain the "unexplainable": A qualitative enquiry of the representations of the caregivers of brain-injured people. Journal of Health Psychology, DOI: $10.1177 / 1359105316642834$

Huynh, T., Alderson, M., Thompson, M. (2008). Emotional labour underlying caring: An evolutionary concept analysis. Journal of Advanced Nursing, 64, 195-208.

Jenkins, R., Rose, J., \& Lovell, C. (1997). Psychological well-being of staff working with people who have challenging behaviour. Journal of Intellectual Disability Research, 41, 502-511.

Jennett, B., \& Plum, F. (1972). Persistent vegetative state after brain damage: A syndrome in search of a name. Lancet 1(7753), 734-737.

Jodelet, D. (1991). Madness and social representations: Living with the mad in one French community. Berkeley: University of California Press.

Johnson, E. K. (2015). The business of care: the moral labour of care workers. Sociology of Health \& Illness, 37, 112-126.

Mann, S. (2005). A health-care model of emotional labour: An evaluation of the literature and development of a model. Journal of Health Organisation and Management, 19, 304-317. 
Michaelsen, J. J. (2012). Emotional distance to so-called difficult patients. Scandinavian Journal of Caring Sciences, 26, 90-97.

Moscovici, S. (1973). Foreword. In C. Herzlich (Ed.), Health and illness (pp. ix-xiv). London: Academic Press.

Pisaniello, S. L., Winefield, H. R., \& Delfabbro, P. H. (2012). The influence of emotional labour and emotional work on the occupational health and wellbeing of south Australian hospital nurses. Journal of Vocational Behavior, 80, 579-591.

Ponsford, J. (2013a). Assessment and management of behaviour problems. , In J. Ponsford, S. Sloan \& P. Snow (Eds.), Traumatic brain injury. Rehabilitation for everyday adaptative living (pp. 164-191). Hove: Psychology Press.

Ponsford, J. (2013b). Dealing with the impact of TBI on psychological adjustment and relationships. In J. Ponsford, S. Sloan \& P. Snow (Eds.), Traumatic brain injury. Rehabilitation for everyday adaptative living (pp.226-262). Hove: Psychology Press.

Rosenthal, D. M. (1986). Two concepts of consciousness. Philosophical Studies, 49, 329-359.

Schmidt, K. H., \& Diestel, S. (2014). Are emotional labour strategies by nurses associated with psychological costs? A cross-sectional survey. International Journal of Nursing Studies, 51, 14501461.

Smith, J. A. (1995). Semi-Structured Interviewing and Qualitative Analysis. In J. A. Smith, R. Harré \& L. V. Langenhove (Eds.), Rethinking methods in psychology (pp. 9-26). London: Sage.

Syed, J. (2008). From transgression to suppression: implications of moral values and societal norms on emotional labour. Gender, Work \& Organization, 15(2), 182-201. 
Tong, A., Sainsbury, P., \& Craig, J. (2007). Consolidated criteria for reporting qualitative research (COREQ): a 32-item checklist for interviews and focus groups. International Journal for Quality in Health Care, 19(6), 349-357.

Tronto, J. (1993). Moral boundaries. A political argument for an ethic of care. Routledge: New-York.

Wagner, W., \& Hayes, N. (2005). Everyday Discourse and Common Sense - The Theory of Social Representations. Basingstoke: Palgrave-Macmillan. 
Table 1 Demographic and professional characteristics of participants.

\begin{tabular}{|c|c|c|c|c|}
\hline & & Specialist & Functional & Total \\
\hline & & residential care & rehabilitation & \\
\hline & & home & centre & \\
\hline Sex & Female & 22 & 13 & 35 \\
\hline & Male & 1 & 1 & 2 \\
\hline Age (y) & $22-30$ & 8 & 1 & 9 \\
\hline & $31-37$ & 4 & 6 & 10 \\
\hline & $38-47$ & 6 & 3 & 9 \\
\hline & $48-57$ & 5 & & 9 \\
\hline & Average (SD) & $37.48(11.49)$ & 40.79 (8.99) & $38.73(10.61)$ \\
\hline Profession & CNA & 14 & 14 & 28 \\
\hline & Medical- & 9 & $0 *$ & 9 \\
\hline & psychological & & & \\
\hline & assistant & & & \\
\hline Length of & $1-4$ & & 4 & 11 \\
\hline service (y) & $5-9$ & & 2 & 10 \\
\hline & $10-15$ & 6 & 4 & 10 \\
\hline & $16-35$ & 2 & 4 & 6 \\
\hline & Average (SD) & $8.49(5.56)$ & $14.14(11.09)$ & $10.63(8.43)$ \\
\hline
\end{tabular}

Abbreviations: y, year; CNA, Certified Nursing Assistant.

* No medical-psychological assistants worked in the functional rehabilitation centre, because it is a health care facility and these professionals work primarily in establishments which offer people social support. 
Table 2 Final interview guide for semi-structured interviews.

Part 1: Exploration of care work with brain-injured people and the relational characteristics of this care work.

What is fulfilling about your job? For you, what is difficult about your job?

Do you think that contact with the brain-injured person is special?

Are special relationship skills required for working with a person with brain injuries?

Part 2: Exploration of the common knowledge of caregivers about people with brain injuries with behavioural disorders.

Does the brain-injured person present behaviour disorders?

How do you recognise them during your daily contacts with people?

How do you differentiate them from other care situations? 
Table 3 Thematic structure of the thematic content analysis.

\begin{tabular}{|c|c|}
\hline Theme & Sub-theme \\
\hline Relational work & $\begin{array}{l}\text { Emotions as a risk for caregivers } \\
\text { Emotional bond between the caregiver and the person with brain injuries }\end{array}$ \\
\hline Emotion & $\begin{array}{l}\text { Anger } \\
\text { Sadness, sense of powerlessness } \\
\text { Fear, anxiety } \\
\text { Negative surprise }\end{array}$ \\
\hline $\begin{array}{l}\text { Aggressive } \\
\text { behaviour }\end{array}$ & $\begin{array}{l}\text { Emotional labour } \\
\text { Consciousness / unconsciousness of the behaviour } \\
\text { Communication (by the transmission of the underlying emotions) } \\
\text { Control (by the caregiver) }\end{array}$ \\
\hline $\begin{array}{l}\text { Management of } \\
\text { situations }\end{array}$ & $\begin{array}{l}\text { To handover to another member of the facility (caregiver, manager) } \\
\text { To bring the brain-injured person back into line } \\
\text { Strategy of emotional labour: surface acting (not expressing emotions), deep } \\
\text { acting (accepting the situation) } \\
\text { Difficulty in managing the situation } \\
\text { Failure in managing the situation }\end{array}$ \\
\hline Position of caregiver & $\begin{array}{l}\text { Work to preserve the relationship } \\
\text { Professional boundaries, professional position }\end{array}$ \\
\hline
\end{tabular}

